\title{
Gender Disparity in the Prevalence of Metabolic Syndrome in Korea: Results from the Korea National Health and Nutrition Examination Survey, 2012
}

\author{
Mee Young $\mathrm{Im}^{1}$ and Gyeong Ae Seomun ${ }^{2}$ \\ ${ }^{1}$ Department of Nursing, Seoil University, Seoul, South Korea \\ ${ }^{2}$ College of Nursing, Korea University, Seoul, South Korea
}

\begin{abstract}
Objectives: To evaluate gender specific characteristics in the prevalence of metabolic syndrome (MetS) and abnormalities in Korean population using the 2009 Joint Interim Statement of the International Diabetes Federation

Methods: We performed a secondary analysis of data based on the 2012 Korea National Health and Nutrition Examination Survey (KNHANES). MetS prevalence was calculated for 5,935 Korean adults ( $\geq 20$ years of age) by sex and age group. Incidence rates of five MetS risk factors were also assessed.

Results: The prevalence of MetS among Koreans was 21.7\% (22.9\% for men, 20.6\% for women). Elderly women after menopause had the highest prevalence of MetS and all five risk factors. Young and middle-aged men had higher prevalence and risk factors of MetS than similarly-aged women, but the rate of MetS in women surged significantly from age 50 and surpassed that of men thereafter. Women had a higher prevalence of low HDL cholesterol than men in all age groups. Of the five MetS risk factors, the prevalence of hypertension was highest $(36.0 \%)$. About one-third of Korean have hypertension as a main risk factor.

Conclusion: We observed a mounting gender disparity with age due to an increase in the prevalence of metabolic abnormalities in female. Preventive strategies including lifestyle interventions and health education about MetS need to be implemented pre-menopausal women and middle-aged men. Therapeutic strategies including drug intervention should be employed for elderly women. In 2012, more than one-fifth of Korean have MetS. These results indicate that MetS is an imperative public health issue that needs to be managed at the national level. Reducing the rates of hypertension and dyslipidemia will be critical to controlling MetS. This study provides not only the latest information but also target population and high risk factors for controlling MetS.
\end{abstract}

Keywords: Metabolic syndrome; Korea; Prevalence; Risk factors

\section{Introduction}

Metabolic syndrome (MetS) is a complex of interrelated risk factors for cardiovascular disease and diabetes [1]. The Third Report of the National Cholesterol Education Program Expert Panel on Detection, Evaluation, and Treatment of High Blood Cholesterol in Adults (NCEP/ATP III), published in 2001, suggests that MetS be diagnosed when a person has three or more of the following five risk factors: (i) abdominal obesity, (ii) hypertension, (iii) glucose intolerance, and dyslipidemia, including (iv) elevated triglycerides or (v) decreased high-density lipoprotein cholesterol [2].

The prevalence of MetS is increasing worldwide. Results of the United States National Health and Nutrition Examination Survey (NHANES), conducted from 1988 to 1994 and then again from 1999 to 2000 , show that the prevalence of MetS in $\geq 20$-year-old adults rose from $29.2 \%$ (1988-1994) to $32.3 \%$ (1999-2000) [3]. Both surveys revealed that more than $50 \%$ of individuals $\geq 60$ years old had MetS based on the NCEP/ATP III definition [3]. In South Korea, results of the 2009 Korea National Health and Nutrition Examination Survey (KNHANES) show that the prevalence of MetS in $\geq 20$-year-old Koreans was $22.4 \%$ (28.3\% of men and $16.6 \%$ of women) [4]. For South Koreans over the age of 30,28.8\% (31.9\% of men and $25.6 \%$ of women) met the diagnostic criteria for MetS, and the number increases each year [5].

MetS is a serious worldwide public health issue [6]. The risk of cardiovascular events and death in people with MetS is significantly increased compared to people without MetS; additionally, the cardiovascular risk conferred by MetS was found to be a third higher in women than in men [7]. As so many people now suffer from MetS, controlling this syndrome is a major public health goal [8].

MetS management in South Korea began in 2009 [9]. By 2012, it was being offered at 25 community health centers in Seoul. MetS management integrates the promotion of various elements of healthful living (e.g., smoking cessation, good nutrition, and physical exercise) to develop a single, multidisciplinary approach that depends on the coordination of medical and health professionals such as doctors, nurses, and dietitians. This approach is intended to result in more effective client-centered disease prevention and health promotion services [8].

MetS is an epidemiological construct of different permutations

*Corresponding author: GyeongAeSeomun, Professor, College of Nursing Korea University, Seoul, South Korea, 136-705, 145, Anam-ro, Seongbukgu, Seoul, South Korea, Tel: 82-02-3290-4920; Fax: 82-02-927-4676; E-mail: seomun@korea.ac.kr

Received October 21, 2014; Accepted January 02, 2015; Published January 05, 2015

Citation: Im MY, Seomun GA (2015) Gender Disparity in the Prevalence of Metabolic Syndrome in Korea: Results from the Korea National Health and Nutrition Examination Survey, 2012. J Diabetes Metab 6: 485. doi:10.4172/21556156.1000485

Copyright: (c) $2015 \mathrm{Im} \mathrm{MY,} \mathrm{et} \mathrm{al.} \mathrm{This} \mathrm{is} \mathrm{an} \mathrm{open-access} \mathrm{article} \mathrm{distributed} \mathrm{unde}$ the terms of the Creative Commons Attribution License, which permits unrestricted use, distribution, and reproduction in any medium, provided the original author and source are credited. 
Citation: Im MY, Seomun GA (2015) Gender Disparity in the Prevalence of Metabolic Syndrome in Korea: Results from the Korea National Health and Nutrition Examination Survey, 2012. J Diabetes Metab 6: 485. doi:10.4172/2155-6156.1000485

of risk factors, each with unique clinical implications and treatment strategies [10]. To develop effective MetS management strategies, it is necessary to investigate target populations and their risk factors (e.g., age- and sex-specific changes in the prevalence of MetS and risk factors among Koreans). Currently, there are rarely published studies on ageand sex-specific changes in MetS prevalence in the national population, but a few studies have examined the KNHANES data to explore MetS prevalence as a function of age over the past 10 years $[8,11]$.

The purpose of this study is to estimate the comprehensive prevalence of MetS and analyze age-specific trends in MetS by sex among the Korean population for the year 2012. Furthermore, we examined the five risk factors of MetS.

\section{Methods}

\section{Study design and population}

This study is a descriptive cross-sectional study through secondary analysis of data from the fifth KNHANES (2012). The KNHANES is a nationwide cross-sectional survey conducted by the Korean Ministry of Health and Welfare (KMHW) and Korea Centers for Disease Control and Prevention (KCDC) and designed to assess the health and nutritional status of the Korean population. All survey procedures and protocols were approved by the Institutional Review Board of the KCDC (IRB: 2012-01EXP-01-2C).

In brief, a stratified multistage probability sampling design was used with selections made from sampling units based on geographical area, sex, and age groups by using household registries (25 strata, 192 clusters). The health interview and health examination survey were performed by trained medical staff and interviewers in mobile examination centers. Through the health examination survey, the anthropometrical, biochemical, and clinical profiles of major noncommunicable diseases were measured. Extrapolation of the findings of KNHANES to the Korean population is possible because of the nature of these nationwide, representative data.

To analyze MetS prevalence by sex, we utilized data for adults aged $\geq 20$ years $(n=5,935$; weighted $\operatorname{sum}=39,021,687)$ who participated in both the health interview and health examination survey among total samples $(n=7,645$, weighted sum $=49,548,733)$.

\section{Definition of MetS and risk factors}

In this study, we used the definition of MetS proposed by the 2009 Joint Interim Statement of the International Diabetes Federation Task Force on Epidemiology and Prevention; National Heart, Lung, and Blood Institute; American Heart Association; World Heart Federation; International Atherosclerosis Society; and International Association for the Study of Obesity [1], with waist circumference cut-off points specific to Korea [12,13]. The Joint Interim Statement defines MetS as the presence of three or more of the following risk factors: (i) hypertension (Systolic Blood Pressure (SBP) $\geq 130 \mathrm{~mm} \mathrm{Hg}$ and/or Diastolic Blood Pressure (DBP) $\geq 85 \mathrm{~mm} \mathrm{Hg}$ ); (ii) abdominal obesity (Waist Circumference (WC) $>90 \mathrm{~cm}$ in men and $>85 \mathrm{~cm}$ in women); (iii) hyperglycemia (Fasting Blood Sugar (FBS) $\geq 100 \mathrm{mg} / \mathrm{dL}$ ); (iv) hypertriglyceridemia (fasting plasma triglycerides (TG) $\geq 150 \mathrm{mg} /$ $\mathrm{dL}$ ); and (v) low high-density lipoprotein cholesterol (HDL-C; fasting HDL-C $<40 \mathrm{mg} / \mathrm{dL}$ in men, $<50 \mathrm{mg} / \mathrm{dL}$ in women).

\section{Statistical analysis}

The sampling weights assigned to study participants were generated by considering complex sample design, non-response rate, and stratification. All analyses were conducted using SAS version 9.3 software with survey procedure (SAS Institute, Inc., Cary, NC, USA) for analyzing complex sample survey data and separated by sex. All data are presented as means or percentages (\%) and standard error (SE). Logistic regression analysis was performed to investigate age-specific trends, and t-test and $\chi^{2}$ test were used to analyze the prevalence of MetS and its risk factors by sex. The reported p-values were two-tailed, and $p<.05$ was considered to be statistically significant.

\section{Results}

Clinical and biochemical characteristics of the study populations are shown in Table 1 . The number of study subjects aged $\geq 20$ years was 5,931 (2,482 men, 3,453 women). The mean age of subjects was 46.2 years (male mean age: 45.1 years; female mean age: 47.3 years). There were statistically significant differences in the clinical characteristics related MetS between males and females-men had higher WC, SBP, DBP, FBS, and TG mean values than women, but women had higher values of low HDL-C than men.

Table 2 shows the numbers of MetS risk factors present in Korean men and women. The overall percentage of healthy Koreans with no risk factors was $32.9 \%$; the percentage of healthy women with no risk factors $(36.2 \%)$ was statistically significantly higher $(p<.001)$ than that of men (29.5\%). In the Korean population, the prevalence of MetS (defined as the presence of three or more of the five risk factors) was $21.7 \%$. Furthermore, approximately one-half of those who had MetS had four or five risk factors.

Table 3 shows the overall prevalence of MetS and its individual risk factors among Koreans. The percentage of men with MetS was significantly higher $(p<.001)$ than that of women $(22.9 \%$ for men versus $20.6 \%$ for women; a difference of $2.3 \%$ ). In Korea, the percentages of

\begin{tabular}{|c|c|c|c|c|}
\hline Characteristics & $\begin{array}{c}\text { Total } \\
(n=5,935) \\
M(S E)\end{array}$ & $\begin{array}{c}\text { Men } \\
(n=2,482) \\
M(S E)\end{array}$ & $\begin{array}{c}\text { Women } \\
(n=3,453) \\
M(S E)\end{array}$ & $P$ \\
\hline $\begin{array}{l}\text { Age (years) } \\
\text { Systolic blood pressure } \\
(\mathrm{mmHg}) \\
\text { Diastolic blood pressure } \\
(\mathrm{mmHg}) \\
\text { Waist circumference }(\mathrm{cm}) \\
\text { Fasting blood sugar }(\mathrm{mg} / \\
\mathrm{dL}) \\
\text { Triglyceride }(\mathrm{mg} / \mathrm{dL}) \\
\text { HDL Cholesterol }(\mathrm{mg} / \mathrm{dL})\end{array}$ & $\begin{array}{c}46.21(0.37) \\
118.00(0.38) \\
76.05(0.24) \\
81.14(0.23) \\
97.48(0.41) \\
135.45(2.36) \\
51.60(0.26)\end{array}$ & $\begin{array}{c}45.12(0.43) \\
120.17(0.42) \\
78.60(0.33) \\
83.99(0.26) \\
98.42(0.47) \\
153.45(3.06) \\
48.62(0.33)\end{array}$ & $\begin{array}{c}47.27(0.45) \\
115.88(0.50) \\
73.56(0.27) \\
78.34(0.32) \\
96.51(0.6) \\
117.16(2.89) \\
54.62(0.33)\end{array}$ & $\begin{array}{c}<0.001 \\
<0.001 \\
<0.001 \\
<0.001 \\
0.008 \\
<0.001 \\
<0.001\end{array}$ \\
\hline
\end{tabular}

Table 1: Clinical and Biochemical Characteristics of the Study Populations.

\begin{tabular}{|l|c|c|c|c|}
\hline No. of risk factors & $\begin{array}{c}\text { Total } \\
(\mathrm{n}=5,935) \\
\%(\mathrm{SE})\end{array}$ & $\begin{array}{c}\text { Men } \\
(\mathrm{n}=2,482) \\
\%(\mathrm{SE})\end{array}$ & $\begin{array}{c}\text { Women } \\
(\mathrm{n}=3,453) \\
\%(\mathrm{SE})\end{array}$ & $P$ \\
\hline 0 & $32.89(0.98)$ & $29.52(1.37)$ & $36.20(1.27)$ & $<0.001$ \\
\hline 1 & $25.17(0.70)$ & $25.19(1.05)$ & $25.14(0.98)$ & $<0.001$ \\
\hline 2 & $20.21(0.65)$ & $22.38(1.11)$ & $18.08(0.81)$ & $<0.001$ \\
\hline Sub total(Non-MS) & $78.27(0.76)$ & $77.09(1.05)$ & $79.42(0.98)$ & $<0.001$ \\
\hline 3 & $12.51(0.53)$ & $14.34(1.76)$ & $10.71(0.62)$ & $<0.001$ \\
\hline 4 & $7.01(0.41)$ & $6.95(0.57)$ & $7.07(0.54)$ & $<0.001$ \\
\hline 5 & $2.21(0.25)$ & $1.62(1.33)$ & $2.80(0.39)$ & $<0.001$ \\
\hline Sub total(MS) & $21.73(0.76)$ & $22.91(1.05)$ & $20.58(0.98)$ & $<0.001$ \\
\hline$P$ determined by logistic regression and $x^{2}$ test. Non-MS=Non-metabolic \\
\hline
\end{tabular}
syndrome; MS=metabolic syndrome

Table 2: The Number of Metabolic Syndrome Risk factors Presence among Koreans $\geq 20$ years. 
Citation: Im MY, Seomun GA (2015) Gender Disparity in the Prevalence of Metabolic Syndrome in Korea: Results from the Korea National Health and Nutrition Examination Survey, 2012. J Diabetes Metab 6: 485. doi:10.4172/2155-6156.1000485

Page 3 of 6

\begin{tabular}{|c|c|c|c|c|}
\hline Characteristics & Total $(n=5,935) \%(S E)$ & Men $(n=2,482) \%(S E)$ & Women $(n=3,453) \%(S E)$ & $P$ \\
\hline Metabolic Syndrome & $21.73(0.76)$ & 22.91(1.05) & $20.58(0.98)$ & $<0.001$ \\
\hline $\begin{array}{l}\text { Blood Pressure } \geq 135 / 85 \mathrm{mmHg} \\
\text { WC }>90 \mathrm{~cm}(\mathrm{M}),>85 \mathrm{~cm}(\mathrm{~F}) \\
\text { FBS } \geq 100 \mathrm{mg} / \mathrm{dL} \\
\mathrm{TG} \geq 150 \mathrm{mg} / \mathrm{dL} \\
\mathrm{HDL}-\mathrm{C}<40 \mathrm{mg} / \mathrm{dL}(\mathrm{M}),<50 \mathrm{mg} / \\
\mathrm{dL}(\mathrm{F})\end{array}$ & $\begin{array}{l}36.02(1.10) \\
24.07(0.97) \\
28.63(0.91) \\
29.89(0.88) \\
29.16(0.80)\end{array}$ & $\begin{array}{l}40.53(1.39) \\
23.48(1.15) \\
31.96(1.25) \\
36.87(1.36) \\
20.38(0.99)\end{array}$ & $\begin{array}{l}31.62(1.41) \\
24.64(1.25) \\
25.25(1.08) \\
22.80(0.92) \\
38.09(1.19)\end{array}$ & $\begin{array}{l}<0.001 \\
0.422 \\
<0.001 \\
<0.001 \\
<0.001\end{array}$ \\
\hline
\end{tabular}

Table 3: Prevalence of Metabolic Syndrome and Risk factors among Koreans $\geq 20$ years.

Prevalence of MetS among $\geq 20$-year-old Koreans by Sex

\begin{tabular}{lcccc}
\hline Age (years) & Total & Men & Women & $P^{*}$ \\
& $\%(\mathrm{SE})$ & $\%(\mathrm{SE})$ & $\%(\mathrm{SE})$ & \\
\hline $20-29$ & $5.56(1.33)$ & $8.06(2.33)$ & $2.77(0.97)$ & 0.013 \\
$30-39$ & $13.74(1.37)$ & $19.53(2.32)$ & $7.65(1.39)$ & $<0.001$ \\
$40-49$ & $21.20(1.41)$ & $23.97(2.07)$ & $18.31(2.11)$ & 0.071 \\
$50-59$ & $29.66(1.76)$ & $32.54(2.66)$ & $26.77(2.20)$ & 0.087 \\
$60-69$ & $39.44(1.93)$ & $37.37(2.89)$ & $41.33(2.49)$ & 0.029 \\
$70 \leq$ & $32.96(1.89)$ & $21.36(2.49)$ & $40.27(2.47)$ & $<0.001$ \\
\hline$P \dagger$ for trend & $<0.001$ & $<0.001$ & $<0.001$ & \\
\hline
\end{tabular}

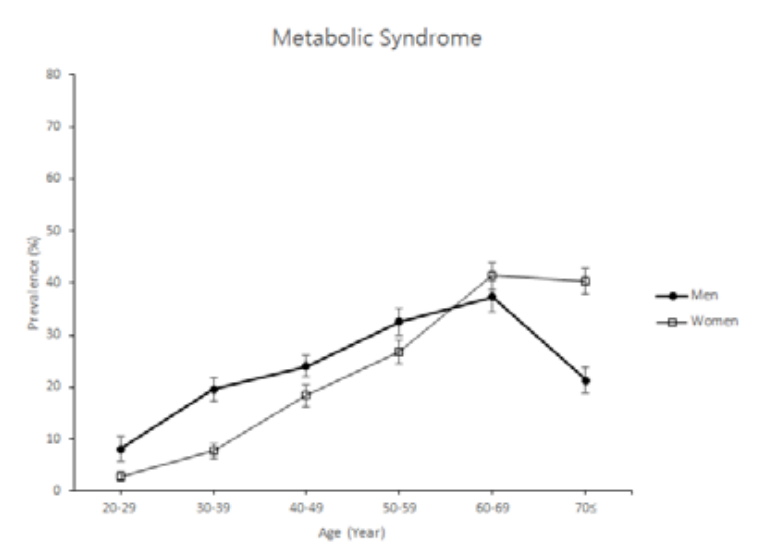

$\mathrm{P} \uparrow$ determined by logistic regression for age-specific trend.

p* determined by $\chi^{2}$ test for comparison prevalence between age group and

sex.

Figure 1: Age-specific prevalence of MetS among $\geq 20$-year-old Koreans by sex.

people possessing each of the five factors-hypertension, abdominal obesity, hyperglycemia, hypertriglyceridemia, and low HDL-Cwere $36.0,24.1,28.6,29.9$, and $29.2 \%$, respectively. Significantly more men than women had hypertension, hyperglycemia, and hypertriglyceridemia $(p<.001)$, but more women than men had low HDL-C $(p<.001)$. The prevalence of abdominal obesity was not statistically different between sexes.

The prevalence of MetS by sex and by age among Korean adults participating in the fifth KNHANES (2012) is shown in Figure 1. The prevalence of MetS in Koreans significantly increased with age in both men and women (p-value for trend: <.001). For Koreans aged 20-59 years, more men than women had MetS, but after age 60, more women than men had MetS (p-value for trend: <.001). The prevalence of MetS in women over 70 years of age was about twice that of men.

Evaluation of the five MetS risk factors on the basis of age and sex reveals that, overall, the prevalence of all five factors significantly increased with age in both men and women (Figure 2; p-values for trend: .008 to <.001). More young and middle-aged (20-59 years) men than women had hypertension, hyperglycemia and hypertriglyceridemia (the significant biggest difference for the 30-39, 50-59, and 30-39 age brackets respectively); rates of abdominal obesity between men and women were not significantly different for these age groups. For Koreans aged 60-69 years, more men than women had hyperglycemia $(p<.003)$, and more women than men had abdominal obesity and low HDL-C (p-values .001 and <.001, respectively); differences between men and women in the prevalence of hypertension and hypertriglyceridemia were not statistically different for this age bracket. For Koreans $\geq 70$ years of age, women surpassed men in terms of prevalence of hypertension $(p=.002)$, abdominal obesity $(p<.001)$, hypertriglyceridemia $(p<.006)$, and low HDL-C $(p<.001)$; differences in the rates of only hyperglycemia between men and women $\geq 70$ years of age were not statistically significant. The prevalence of low HDL-C in women was significantly higher than in men in all age groups ( $p$-values of .004 and <.001). The sex disparity with respect to the percentage of people with low HDL-C widened with age; at age 50 and above, the prevalence of low HDL-C in women was about twice that of men (mean difference of $17.7 \%, p<.001$ ).

\section{Discussion}

Based on the definition of MetS from the 2009 Joint Interim Statement, the prevalence of MetS in the Korean population was $21.7 \%$ in 2012, which translates to about 8.5 million Koreans (more than one-fifth of the population). MetS is common in Korean adults. These results are consistent with earlier analyses of MetS prevalence in Korea 
Citation: Im MY, Seomun GA (2015) Gender Disparity in the Prevalence of Metabolic Syndrome in Korea: Results from the Korea National Health and Nutrition Examination Survey, 2012. J Diabetes Metab 6: 485. doi:10.4172/2155-6156.1000485

\begin{tabular}{lcccr}
\multicolumn{2}{l}{ Prevalence of High BP among } & \multicolumn{5}{l}{$\geq 20$-year-old Koreans by Sex } \\
\hline Age (years) & $\begin{array}{c}\text { Total } \\
\text { \%(SE) }\end{array}$ & \multicolumn{1}{l}{$\begin{array}{l}\text { Men } \\
\text { \%(SE) }\end{array}$} & \multicolumn{1}{l}{$\begin{array}{l}\text { Women } \\
\text { \%(SE) }\end{array}$} & \multicolumn{2}{l}{$P^{*}$} \\
\hline $20-29$ & $11.95(1.77)$ & $19.66(3.26)$ & $3.47(1.14)$ & $<0.001$ \\
$30-39$ & $19.38(1.65)$ & $28.74(2.62)$ & $9.61(1.79)$ & $<0.001$ \\
$40-49$ & $31.79(1.92)$ & $39.11(2.69)$ & $24.15(2.45)$ & $<0.001$ \\
$50-59$ & $46.76(2.01)$ & $52.50(2.94)$ & $40.99(2.59)$ & 0.002 \\
$60-69$ & $63.23(1.86)$ & $64.96(2.68)$ & $61.65(2.52)$ & 0.363 \\
$70 \leq$ & $70.26(1.57)$ & $62.91(2.94)$ & $74.86(2.16)$ & 0.002 \\
\hline$P \dagger$ for trend & $<0.001$ & $<0.001$ & $<0.001$ & \\
\hline
\end{tabular}

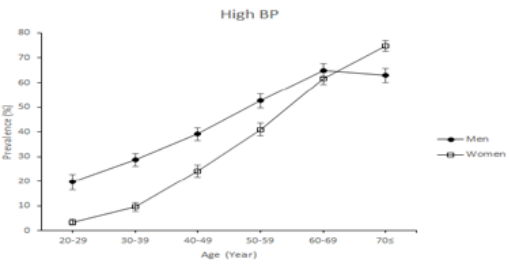

Figure 2-A Age-specific prevalence of High BP among $\geq 20$-year-old Koreans by sex

Prevalence of Abdominal Obesity among $\geq 20$-year-old Koreans by Sex

\begin{tabular}{lcrrr}
\hline Age (years) & $\begin{array}{c}\text { Total } \\
\%(\mathrm{SE})\end{array}$ & $\begin{array}{l}\text { Men } \\
\text { \%(SE) }\end{array}$ & \multicolumn{1}{l}{$\begin{array}{l}\text { Women } \\
\%(\mathrm{SE})\end{array}$} & \multicolumn{1}{l}{$P^{*}$} \\
\hline $20-29$ & $13.25(1.88)$ & $17.14(2.75)$ & $8.94(1.94)$ & 0.005 \\
$30-39$ & $21.67(1.59)$ & $25.20(2.42)$ & $17.95(2.15)$ & 0.029 \\
$40-49$ & $22.00(1.55)$ & $21.92(2.33)$ & $22.09(2.09)$ & 0.957 \\
$50-59$ & $25.90(1.71)$ & $25.40(2.38)$ & $26.40(2.22)$ & 0.745 \\
$60-69$ & $37.93(2.21)$ & $30.42(2.97)$ & $44.81(2.70)$ & 0.001 \\
$70 \leq$ & $33.59(1.98)$ & $24.37(2.43)$ & $39.36(2.57)$ & $<0.001$ \\
\hline$P \dagger$ for trend & $<0.001$ & 0.008 & $<0.001$ &
\end{tabular}

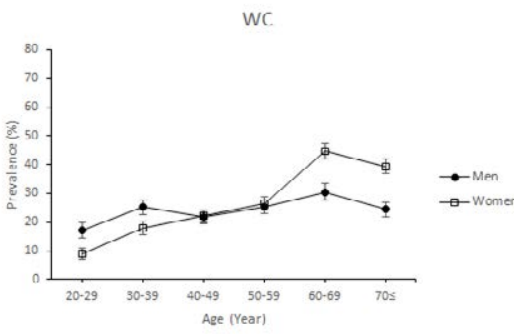

Figure 2-B Age-specific prevalence of abdominal obesity among $\geq 20$-year-old Koreans by sex

Prevalence of Hyperglycemia among $\geq 20$-year-old Koreans by Sex

\begin{tabular}{lcccr}
\hline $\begin{array}{l}\text { Age } \\
\text { (years) }\end{array}$ & \multicolumn{1}{c}{$\begin{array}{c}\text { Total } \\
\text { \%(SE) }\end{array}$} & \multicolumn{1}{c}{$\begin{array}{c}\text { Men } \\
\text { (SE) }\end{array}$} & $\begin{array}{l}\text { Women } \\
\%(\text { SE })\end{array}$ & \multicolumn{1}{c}{$P^{*}$} \\
\hline $20-29$ & $7.35(1.46)$ & $9.77(2.26)$ & $4.54(1.71)$ & 0.071 \\
$30-39$ & $15.96(1.55)$ & $20.84(2.53)$ & $10.73(1.62)$ & 0.004 \\
$40-49$ & $26.09(1.71)$ & $28.68(2.52)$ & $23.29(2.20)$ & 0.100 \\
$50-59$ & $40.28(1.83)$ & $48.37(2.97)$ & $32.02(2.03)$ & $<0.001$ \\
$60-69$ & $53.99(2.02)$ & $59.77(2.84)$ & $48.57(2.71)$ & 0.003 \\
$70 \leq$ & $48.20(1.71)$ & $46.44(2.60)$ & $49.37(2.13)$ & 0.818 \\
\hline$P \dagger$ for & & & &
\end{tabular}

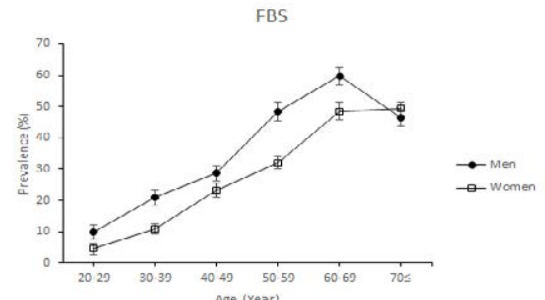

trend $\quad<0.001 \quad<0.001 \quad<0.001$

Figure 2-C Age-specific prevalence of hypergycemia among $\geq 20$-year-old Koreans by sex

Prevalence of Hypertriglyceridemia among $\geq 20$-year-old Koreans by

\begin{tabular}{lccrr}
$\begin{array}{l}\text { Sex } \\
\text { Age } \\
\text { (years) }\end{array}$ & $\begin{array}{c}\text { Total } \\
\%(\text { SE) }\end{array}$ & $\begin{array}{l}\text { Men } \\
\%(\text { SE) }\end{array}$ & \multicolumn{1}{l}{$\begin{array}{l}\text { Women } \\
\%(\text { SE) }\end{array}$} & \multicolumn{1}{l}{$P^{*}$} \\
\hline $20-29$ & $14.26(2.26)$ & $20.73(3.67)$ & $6.96(1.66)$ & $<0.001$ \\
$30-39$ & $24.73(1.78)$ & $36.62(2.85)$ & $12.04(1.72)$ & $<0.001$ \\
$40-49$ & $33.92(1.63)$ & $43.00(2.48)$ & $24.10(2.20)$ & $<0.001$ \\
$50-59$ & $41.07(1.90)$ & $50.11(2.94)$ & $31.77(2.58)$ & $<0.001$ \\
$60-69$ & $35.82(1.79)$ & $36.33(2.84)$ & $35.32(2.55)$ & 0.803 \\
$70 \leq$ & $31.10(2.19)$ & $24.47(3.11)$ & $35.50(2.74)$ & 0.006 \\
\hline$P \dagger$ for & $<0.001$ & 0.003 & $<0.001$ & \\
trend & & &
\end{tabular}

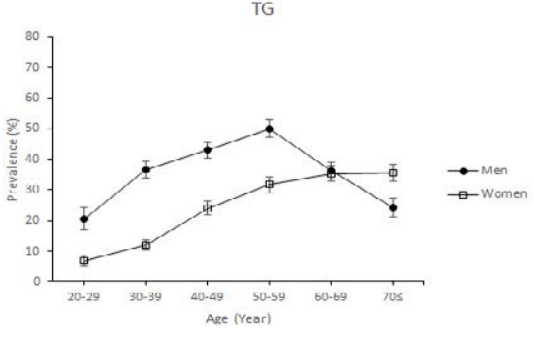

Figure 2-D Age-specific prevalence of Hypertriglyceridemia among $\geq 20$-year-old Koreans by sex

\begin{tabular}{|c|c|c|c|c|}
\hline \multicolumn{5}{|c|}{ Prevalence of Low HDL-C among } \\
\hline $\begin{array}{l}\text { Age } \\
\text { (years) }\end{array}$ & $\begin{array}{c}\text { Total } \\
\%(\mathrm{SE})\end{array}$ & $\begin{array}{c}\text { Men } \\
\%(\mathrm{SE})\end{array}$ & $\begin{array}{l}\text { Women } \\
\%(\mathrm{SE})\end{array}$ & $P^{*}$ \\
\hline $20-29$ & $18.06(2.07)$ & $13.06(2.69)$ & $23.70(2.72)$ & 0.004 \\
\hline 30-39 & $24.36(1.52)$ & $17.68(1.97)$ & $31.50(2.41)$ & $<0.001$ \\
\hline $40-49$ & $31.02(1.70)$ & $22.56(2.18)$ & $40.17(2.61)$ & $<0.001$ \\
\hline $50-59$ & $33.07(1.75)$ & $24.93(2.33)$ & $40.46(2.37)$ & $<0.001$ \\
\hline $60-69$ & $35.75(1.79)$ & $24.08(2.52)$ & $46.91(2.48)$ & $<0.001$ \\
\hline $70 \leq$ & $40.71(1.86)$ & $22.51(2.68)$ & $52.79(2.31)$ & $<0.001$ \\
\hline $\begin{array}{l}P \dagger \text { for } \\
\text { trend }\end{array}$ & $<0.001$ & $<0.001$ & $<0.001$ & \\
\hline
\end{tabular}

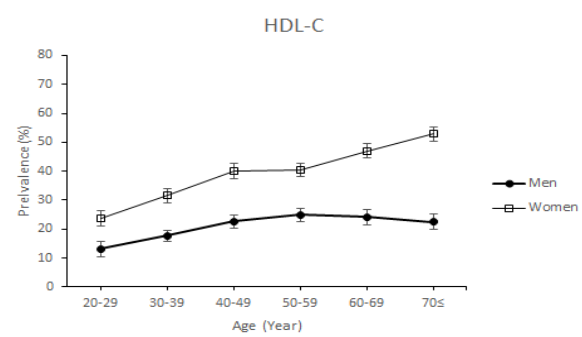

Figure 2-E Age-specific prevalence of HDL-C among $\geq 20$-year-old Koreans by sex

$\mathrm{P} \dagger$ were determined by logistic regression for age-specific trend. $\mathrm{p}^{*}$ determined by $\chi^{2}$ test for comparison prevalence between age group and $\operatorname{sex}$

Figure 2: Age-specific prevalence of risk factors among $\geq 20$-year-old Koreans by sex. 
Citation: Im MY, Seomun GA (2015) Gender Disparity in the Prevalence of Metabolic Syndrome in Korea: Results from the Korea National Health and Nutrition Examination Survey, 2012. J Diabetes Metab 6: 485. doi:10.4172/2155-6156.1000485

$[4,14]$. The $21.7 \%$ figure is slightly lower than a value of $22.9 \%$ for the U.S. adult population from 2009-2010 reported in a recent study [10].

The value of $21.7 \%$ in this study shows that the prevalence of MetS had increased in Korea, compared to $15.7 \%$ of Koreans having MetS in 1998 , and $14.4 \%$ in 2001 [11]. Lim et al. [15] reported a similar trend among Korean (24.9\% in 1998 to $31.3 \%$ in 2007). In recent years, however, MetS prevalence in Koreans has begun to decrease slightly, from $22.4 \%$ in 2009 to $21.7 \%$ in 2012 (based on the same criteria for MetS diagnosis) [4]. We could not compare further with the prevalence of other researches for Korean because those studies used different criteria for MetS diagnosis.

Results show that MetS prevalence in Koreans significantly increased with age up to the 60-69 years age bracket in both men and women, and decreased for the $\geq 70$ years age group. We observed a disparity in the rate of MetS between men and women-for ages 20-59 years, more men than women had MetS, whereas the incidence of MetS in women surged sharply at age 60 years (from $26.7 \%$ for $50-59$ years to $41.3 \%$ for $60-69$ years) and surpassed that of men thereafter. This difference is consistent with the results of other research $[15,16]$. In this study, however, the turning point for the change in MetS prevalence was 60 years in both sexes, compared to 50 years in other analyses of Koreans [15].

Considering that this remarkable increase in MetS in women begins around age 50-60 years, it seems possible that menopause could be a contributing factor in this dramatic change. Similar sharp increases in all five risk factors (e.g., hypertension, abdominal obesity, hyperglycemia, hypertriglyceridemia and low HDL-C) in women from the 40-49 to 50-59 and 60-69 years age brackets support this hypothesis. These changes may be a result of estrogen deficiency in menopause. The transition from pre- to postmenopause is associated with the emergence of many of the metabolic syndrome including increased intraabdominal fat, atherogenic lipid profile with increased low density lipoprotein and triglycerides levels, reduced high density lipoprotein, and glucose levels $[17,18]$.

The most high-risk groups were women in the $60-69$ and $\geq 70$ years age brackets, for which the prevalence of MetS was 41.3 and $40.3 \%$, respectively. The secondary risk groups were men in the 50-59 and 6069 years age brackets, for which the prevalence of MetS was 32.5 and $37.4 \%$, respectively. Education about MetS and preventive programs for women before the onset of menopause (i.e., women between the ages of 40 and 50 years) would be beneficial. Preventive programs including lifestyle changes such as regular exercise, smoking cessation, healthy diet with low fat and sodium, and weight control should be initiated prior to menopause women and young and middle-aged men. Therapeutic strategies should be targeted to for women age 60 and over.

Of the five risk factors for MetS, hypertension was the most prevalent, found in $36.0 \%$ of Koreans ( $40.5 \%$ of men, $31.6 \%$ of women). This is equal to more than one-third of the population based on the criteria for MetS outlined in the 2009 Joint Interim Statement. Hypertension played a leading role in the high prevalence of MetS. From ages 20 to 59 years, significantly more men had hypertension than women; for the 60-69 years age group, the incidence of hypertension in men and women was about equal (65.0 and $61.7 \%$, respectively). From the 60-69 to the $\geq 70$ years age group, the prevalence of hypertension deceased in men, but continued to rise in women. For Koreans 70 years of age and older, the incidence of hypertension in women was significantly higher than in men. The most at-risk group was women $\geq 70$ years of age ( $74.9 \%$ had hypertension). Individuals in this age group with hypertension would benefit from immediate hypertension therapy and management. Other high-risk groups-with $>60 \%$ hypertension incidence rates-were women aged 60-69 and men aged 60-69 and $\geq 70$ years. Individuals more than 50 years old (both sexes) also had high rates of hypertension $(>40 \%)$. National strategies for hypertension prevention and treatment are urgently needed for Koreans $\geq 50$ years of age.

Waist circumference increased with age in both sexes, the prevalence of abdominal obesity was higher in men up to 39 years than women, while it was higher $\geq 50$ years in women. Women aged 60-69 years group had the highest prevalence $(44.8 \%)$. The prevalence of hypertriglyceridemia was higher in men $\geq 20$ years of age $(36.9 \%)$ compared to women $(22.8 \%$, a difference of $14.1 \%)$, and $40-59$ years age group in men had the highest prevalence. Fasting blood sugar increased with age in both sexes, with high prevalence in men $\geq 50$ years and in women $\geq 60$ years, similar to the other risk factors. The prevalence of low HDL-C was very high in women $\geq 20$ years of age compared to men $(20.4 \%$ in men and $38.1 \%$ in women, a difference of $17.7 \%)$. There were big gaps between sexes. Women had higher prevalence of low HDL-C than men in all age groups. The sex-based difference of these risk factors may be a direct result of ovarian failure or, alternatively, an indirect result of the metabolic consequences of central fat redistribution with estrogen deficiency after menopause [17].

Similar trends were observed for MetS and five factors. Women aged $\geq 50$ years in particular had very high rates of MetS and all risk factors, whereas young and middle-aged groups of men had higher rates of hypertension, abdominal obesity, hyperglycemia, hypertriglyceridemia, and MetS than same-aged women. Hypertension (primarily) and hypertriglyceridemia, low HDL-C, and hyperglycemia (secondarily) all played major roles in MetS increases.

\section{Conclusion}

We observed a mounting gender disparity with age due to an increase in the prevalence of metabolic abnormalities in female. In 2012, more than one-fifth of Korean have MetS. These results indicate that MetS is an imperative public health issue that needs to be managed at the national level. Preventive strategies including lifestyle interventions and health education about MetS need to be implemented pre-menopausal women and middle-aged men. Therapeutic strategies including drug intervention should be employed for elderly women. Reducing the rates of hypertension and dyslipidemia will be critical to controlling MetS. This study provides the latest information but also sex and age specific target population and high risk factors for controlling MetS.

Furthermore, research is needed to identify the relationship an explosive increase and menopause, gender and age specific related factors and education program about MetS.

\section{Acknowledgment}

The present research has been conducted by the Research Grant of Seoil University in 2012

\section{References}

1. Alberti K, Eckel RH, Grundy SM, Zimmet PZ, Cleeman Jl, et al. (2009) Harmonizing the metabolic syndrome: A joint interim statement of the international diabetes federation task force on epidemiology and prevention National heart, lung, and blood institute; American heart association; World heart federation; International atherosclerosis society; and International association for the study of obesity. Circulation 120: 1640-1645. 
Citation: Im MY, Seomun GA (2015) Gender Disparity in the Prevalence of Metabolic Syndrome in Korea: Results from the Korea National Health and Nutrition Examination Survey, 2012. J Diabetes Metab 6: 485. doi:10.4172/2155-6156.1000485

Page 6 of 6

2. National Institute of Health (2001) Executive summary of the third report of the National Cholesterol Education Program (NCEP): Expert panel on detection, evaluation and treatment of high blood cholesterol in adults (Adult Treatment Panel, ATP III). JAMA 285: 2486-2497.

3. Ford ES, Giles WH, Mokdad AH (2004) Increasing prevalence of the metabolic syndrome among U.S. adults. Diabetes Care 27: 2444-2449.

4. Im MY, Lee YR, Han SJ, Cho CM (2012) The Effect of lifestyle factors on metabolic syndrome among Korean adults. Journal of Korean Academy of Community Health Nursing 23: 13-21.

5. Ministry for Health and Welfare (2012) Korea health statistics 2007-2010. Korean national health and nutrition examination survey, Seoul, Korea

6. Zimmet P, Magliano D, Matsuzawa Y, Albert G, Shaw J (2005) The metabolic syndrome: A global public health problem and a new definition. Journal of Atherosclerosis and Thrombosis 12: 295-300.

7. Gami AS, Witt BJ, Howard DE, Erwin PJ, Gami LA, et al. (2007) Metabolic syndrome and risk of incident cardiovascular events and death: A systematic review and meta-analysis of Iongitudinal studies. Journal of the American College of Cardiology 49: 403-414.

8. Kim HS, Yoon SJ, Lee KS, Kim HS, Oh SW, et al. (2011) Effects of a selfmanagement program for metabolic syndrome -a metabolic syndrome management program in Seoul-. Korean Journal of Health Education and Promotion 28: 51-62.

9. Seoul Metropolitan Government. Guidebook for the management of metabolic syndrome of Seoul citizen. Seoul, Korea.

10. Beltrán-Sánchez H, Harhay MO, Harhay MM, McElligott S (2013) Prevalence and trends of metabolic syndrome in the adult U.S. population, 1999-2010. Journal of the American College of Cardiology 62: 697-703.

11. 11. Park HS, Kim SM, Lee JS, Lee J, Han JH, et al. (2007) Prevalence and trends of metabolic syndrome in Korea: Korean national health and Nutrition Survey 1998-2001. Diabetes, Obesity and Metabolism 9: 50-58.

12. Lee SY, Park HS, Kim SM, Kwon HS, Kim DY, et al. (2006) Cut-off points of waist circumference for defining abdominal obesity in the Korean population. Korean J Obes 15: 1-9.

13. Lee SY, Park HS, Kim DJ, Han JH, Kim SM, et al. (2007) Appropriate waist circumference cutoff points for central obesity in Korean adults. Diabetes Research and Clinical Practice 75: 72-80.

14. Park E, Choi SJ, Lee HY (2013) The Prevalence of metabolic syndrome and related risk factors based on the KNHANES V 2010. J Agric Med Community Health 38: 1-13.

15. Lim S, Shin H, Song JH, Kwak SH, Kang SM, et al. (2011) Increasing prevalence of metabolic syndrome in Korea: the Korean national health and nutrition examination survey for 1998-2007. Diabetes Care 34: 1323-1328.

16. Ford ES, Giles WH, Dietz WH (2002) Prevalence of the metabolic syndrome among US adults: Findings from the third national health and nutrition examination survey. JAMA 287: 356-359.

17. Carr MC (2003) The emergence of the metabolic syndrome with menopause. $J$ Clin Endocrinol Metab 88: 2404-2411.

18. Schubert CM, Rogers NL, Remsberg KE, Sun SS, Chumlea WC, et al. (2006) Lipids, lipoproteins, lifestyle, adiposity and fat-free mass during middle age: the Fels Longitudinal Study. Int J Obes (Lond) 30: 251-260. 